\title{
On Graphic Design in Visual Packaging Design
}

\author{
Chuncai Zhang \\ Huanghe Science and Technology College \\ Zhengzhou, China 450046
}

\begin{abstract}
The graphics in visual packaging image design conveys the commodity's relevant information to the audiences using its intuitive, interesting and vivid and rich expression, to arouse the audiences' mental response, and eventually generate resonance among them. Through analysis and sorting of the graphic elements in visual packaging image design, this paper summarizes the expression forms and design rules of the visual packaging image of graphic design. And take this as an entry point, deduces the methods of graphic design of visual packaging image in combination with visual language of graphic design and its function of conveying information, and give new visual appeal to the graphic design, thus to make the graphic conveys the commodity's information in a correct, fast and successful way, to make the commodity stand out from the vast commodities in the commodity homogeneity era of today, and arouse resonance among audiences, enhance the commodity's cognition and the brand awareness.
\end{abstract} design

Keywords—visual packaging image; visual elements; graphic

\section{INTRODUCTION}

In packaging visual image design, the visual elements such as graphics, words and colors make a visual expression of the products, thus conveys relevant information of the product directly or indirectly to the audiences, arouse their resonance, to further attract the audiences' sight to relevant information of the product, to make the audiences have a comprehensive understanding of the product's brand and contents on the basis of certain interest in products. As one of the main visual elements, graphic plays an important role in the transmission of information. And graphic design is particularly important, which is directly related to the accuracy of the conveyed product information and the acceptance degree of the information by audiences.

\section{CONTENT OF GRAPHIC DESIGN OF VISUAL PACKAGING IMAGE}

\section{A. Logo Design}

Logo design mainly includes the trademark, corporate logo and other identifiers. Trademark is the commodity mark that has been registered in the State Trademark Bureau, representing the identity of the commodity, and it is protected by the trademark law; corporate logo is a representative of the enterprise image and enterprise name. In order to convey information definitely and clearly, avoid the cost burden brought by repeated advertising, many corporate logos are not only the representative of enterprise image, but also the representatives of the commodity. For instance, the unity of enterprise name and commodity's brand name of "Apollo Group", the sign of "Haier Group" and so on, all have the unified logo image; other identifiers are mainly the special mark for national quality certification and the mark for industry standard certification, such as, quality certification marks, green environmental protection marks, green food marks, etc., the transportation and recycling logo in circulation and sales process etc. The application of these identifiers directly conveys relevant information of the enterprises and commodity, which is also the representative of commodity quality and reputation, aiming to enhance the connection between enterprise and audiences, and promote brand cognition and brand awareness among the audiences.

\section{B. Commodity Image}

In numerous visual packaging images, most of the graphic design tends to express with visual elements relating to the contents, especially the food packaging image, often conducts realistic expression through the modern advanced photography technique. In addition to some open-window types of design, we cannot directly see the real image of the commodity within the package. We should make a flatten visual display of the commodity's real image through corresponding graphical visual elements, and apply specific graphic elements to the limited packaging display surface through different creation methods, to enhance the impact of visual packaging image and visual symbolic.

\section{EXPRESSION OF GRAPHIC DESIGN OF THE VISUAL PACKAGING IMAGE}

The visual packaging image differs a lot against different commodities, and great difference also exists in the expression methods and the forms of graphic design. For example, there exists the realistic expression directly using the commodity's specific image, and conducts information of the application of modern photography skills through the display of various modern commercial illustration, and communicates the emotion between the commodity and audiences. Such concrete graphic design can express different visual effect against different contents using a variety of painting materials and tools, to shape out various unique and novel modeling. Through the application of realistic and various other methods, we can express feelings freely, display rich visual illusions, describe the imaginary space beyond space and time, enhance visual image of the commodity, and arouse audience's psychological resonance. 
Most of the modern fashion visual packaging images adopt abstract graphic design, and mainly uses the free formation method of dot, line and surface, to make summary, induction and refining of the information to be conveyed by the commodity, thus to create a geometric abstract graphics. For example, use some organic graphics, accidental graphics and computer generated graphics to express relevant information of commodity packaging. The visual packaging image designed using abstract graphic often gives the audiences a kind of rational and rigorous sense of order, at the same time, it can enhance visual impact of the packaging image, catch the attention of audiences, induce the audiences' psychological recognition, thereby achieve the advertising effect of commodity publicity and promotion.

In addition, the application of decoration graphics and cartoon characters in visual packaging image is also quite common. Decorative graphic is a kind of graphic refined, processed and created against natural forms to describe the commodity's relevant information and specific form through the combination of subjective consciousness and objective content, having strong visual rhythm beauty. The cartoon characters are also used widely, which can play the role of "spokesperson ", and is connecting with the enterprise image directly, being the good medium between enterprise and goods and the audiences. The design of cartoon modeling should combine the property and connotation of the commodity, and the exaggerated, humorous, lively and lovely images are often adopted, its name shall be concise, easy to remember and catchy, rendering it strong personality and cultural connotation. The graphic design of visual packaging image shall take the characteristics and connotation of subject content into full consideration, and conduct graphic design in combination with the commodity's relevant information, using different expression methods, enabling graphic design present the good visual image of enterprises and products, thus to establish complete feeling of graphic design among the audiences, won the audiences' recognition, and improve the overall image of enterprise and commodity.

\section{SUITABILITY AND SPECIFICITY OF GRAPHIC DESIGN OF VISUAL PACKAGING IMAGE}

The application and expression of graphic design in visual packaging image will be closely combined with the related attributes of enterprises and commodities, no matter the concrete graphics, abstract graphics or the decorative graphics and cartoon characters are adopted, the association and novelty of the graphic shall be taken into consideration, to make it glow strong vitality, create an atmosphere that can arouse the audiences' psychological resonance, and transfer it to the visual language of packaging image.

\section{A. Suitability}

The design of packaging image graphics is inseparable from the designer's life experience. The designer's emotion and cognition toward enterprises, commodities and related matters have a direct impact on the choice of graphic elements. They should have an in-depth and comprehensive understanding of the commodities, learn about the audiences' consumption psychology and consumption characteristics, and conduct sufficient analysis and understanding of the experience that has been acquired. And in specific process of creation, they shall have a clear and sufficient understanding of the selected visual elements' forms and structures, providing the premise conditions for the creation of suitable graphics.

While designing, the attention shall be paid to the communication of "meaning" and suitability of "form". The visual elements that adapt to the subject shall be selected and lay emphasis on the echoing, relying and conformity among visual elements, and recreate them using all kinds of expression methods. Such recreation is to conclude, refine and apply the selected visual elements with modern aesthetic idea. Redesign and recombine them using the well-known images, and combine them together in the display surface of packaging image. The whole process of graphic design creation shall be reflected in the cut-in process of looking for graphic combination, and the accuracy of the entry point directly influences the graphic's suitability. First of all, the cultural connotation and visual characteristics of the selected visual elements shall be sorted out, and develop design from the form of elements. Then create specific modeling of graphics, the connection between graphics and the negative space presented after combination of graphics on the basis of the interlinked "meaning". These visual elements present a unified and perfect overall image through mutual cooperation and mutual adaptation. Start from these several aspects simultaneously and carry out the design among elements. Take specific modeling of the graphic as the entry point, and involve in other related elements, lay emphasize on the sharing and interlink of the modeling. Such sharing and interlink are mainly reflected in the elements involved in combination, the modeling, size and weight, reflecting the relation of primary and secondary and rich visual perception as well as the complete unified graphics, so as to improve the visual unity of visual packaging image.

\section{B. Specificity}

The purpose of graphic design of visual packaging image is to convey the concept and emotion of enterprise commodity. Concept refers to the material connotation that design shall follow, and emotion refers to the spiritual connotation that design shall follow. As the main carrier to convey enterprise commodity information, graphics need to be converted to the visual image for information conveying. Among the vast similar packaging images, if you want to highlight the graphic image force, you should grasp the application and expressiveness of graphics, and lay emphasis on the novelty and uniqueness of graphic design.

We shall pay attention to the novelty of "meaning" and the uniqueness of "form". The "meaning" of graphics in visual packaging images is the key that audiences may be interested in its visual modeling. People all have high interest and longing for new and beautiful modeling, and the profound meaning expressed by the graphics in packaging image directly affects the audiences' acceptance of the commodities. Therefore, the graphic design of packaging image should be simply the statement of "meaning", but a kind of cultural accumulation after refining, which is a creation. Together with the main idea of related information, it forms a part of the entirety, which is a kind of humanistic spirit that can be 
perceived by the audiences. This requires the graphic design of visual packaging image has strong novelty. Differing from the single plane design, the visual packaging design is threedimensional. The various display surfaces of packaging design and the integral connection among them shall be taken into consideration, but the too unified monotony shall be broke away, to make the relationship between the graphic elements full of vitality, rendering some interesting and strange feeling to the graphics. To conduct conclusion, refining and selection of the graphic elements using the highly concise expression skills, reflecting the distinct sense of the times of graphic design simply. At the same time, the audiences' consumption psychology shall be taken into full consideration, and in order to make render strong attraction to the graphics of visual packaging image, certain uniqueness shall be given to the graphics. The visual image with individuality may arouse audiences' attention and interest, thus stimulate their purchasing desire.

James, the British packaging designer says that the modern market requires packaging make a permanent impression unforgettable impression "using attraction instead of screaming". In graphic design of visual packaging image, the reference and applicant of graphic elements shall not be interpreted as simple and mechanical combination. The adaptation is not referred to simple combination of multiple visual elements relating to the commodity information and put into one picture. Therefore, we shall deduce the relevant graphics using modern design awareness and method through application of various expression methods of graphic design and the specific graphic cultural connotation in combination with the theme and contents to be expressed by the visual packaging image design, and give new meaning and new visual appeal to the graphics, and light up the vitality and symbol force of visual images. And continue and develop the visual vocabulary of visual packaging image design on the basis of aforementioned, so as to enrich the expression form and expression methods of graphic design, and make modern visual packaging image design has a more profound cultural connotation and more diversified artistic expression space.

\section{REFERENCES}

[1] Yang Renmin. Packaging Design. Chongqing: Southwest China Normal University Press, 2005.

[2] Xiao He. Sale Packaging Design. Beijing: Printing Industry Press, 2008.

[3] Wang Hong. Analytical Paradigm Navigation of Commercial Packaging Design Creativity. Beijing: Tsinghua University Press, 2007.

[4] Tang Yong. "People Oriented" Packaging Design Concept [J]. Print Today, 2010.

[5] Lin Qian. On the Value-added effect of Innovated Packaging Design on Products [J]. Packaging Engineering, 2010.

[6] Liu Ying, Yang Meng. Study on Application of "Five Senses" in Packaging Design [J].Packaging Engineering, 2011. 